\title{
OS PRESSUPOSTOS TEÓRICOS DA PSICOLOGIA SUBJACENTES À TERAPIA LEIGA E SUAS FORMAS DE INSTITUCIONALIZAÇÃO
}

\author{
Sanyo Drummond Pires \\ (Universidade Federal da Grande Dourados - UFGD)
}

\begin{abstract}
Resumo
A Terapia Leiga foi um modelo de organização de tratamento do alcoolismo, desenvolvida nos EUA na primeira metade do século vinte. Devido ao caráter muitas vezes inédito de suas concepções teóricas e técnicas e à pluralidade de formas de sua institucionalização, a Terapia leiga foi um modelo de grande influência para os modelos posteriores de abordar o tratamento do alcoolismo, tanto em instituições religiosas ou de ajuda mútua, quanto em modelos de atenção clínica ou social sobre o assunto. Procurou-se nesse artigo explicitar suas principais contribuições para o tema por meio das teorias de seus principais autores, bem como o processo de mudança pela qual o movimento passou nas suas diferentes formas de institucionalização.
\end{abstract}

Palavras chave: Terapia Leiga; Alcoolismo; Movimento Emmanuel; Doze Passos.

\section{Abstract \\ The theoretical assumptions of psychology underlying Lay Therapy and its forms of institutionalization.}

The Lay Therapy was a alcoholism model of treatment, developed in the USA in the first half of the twentieth century. Due to the often unprecedented feature of its theoretical and technical conceptions and to the plurality of forms of its institutionalization, Lay Therapy was a model of great influence for the later models to approach the treatment of alcoholism, either in religious institutions or of mutual aid, As well as models of clinical or social attention on the subject. This article explores the main contributions to the theme through the theories of its main authors, as well as the process of change through which the movement has gone through its different forms of institutionalization.

Key words: Lay Therapy; Alchoholism; Emmanuel Movement; Twelve Steps.

\section{Introdução}

A questão da dependência química, e os problemas dela decorrentes em nossa sociedade são objetos de grande debate acadêmico, social e por parte dos formuladores de políticas públicas. No entanto, como essa mobilização envolve uma multiplicidade de agentes, a compreensão dos processos explicativos tanto das causas quanto das possíveis ações para sanar os problemas decorrentes da dependência vai variar muito (Pilon \& Luis, 2004; Garcia, Leal \& Abreu, 2008). 
Dentre essas diversas perspectivas, uma, no entanto, merece um destaque em especial, primeiro por ser o modelo mais difundido e disponível (Silva Figueiró, 2014), mas também por sua especificidade de questionar a pretensão de uma saída técnica para a questão da dependência. Composta por diversos grupos essa perspectiva geralmente é nomeada como "grupos de ajuda mútua (Mota, 2014). Tais tratamentos, presentes principalmente em grupos como os Alcoólicos Anônimos, Narcóticos Anônimos e outros semelhantes se baseiam, em sua grande maioria, no modelo de tratamento dos Doze Passos, proposto inicialmente, na sua formulação mais estruturada e conhecida atualmente, pelos Alcoólicos Anônimos, e presente no livro dos Doze Passos e as Doze tradições (Alcoólicos Anônimos, 1971).

O modelo dos doze passos, voltado para o tratamento da dependência química, e estruturado incialmente para a dependência de álcool, deve ser entendido, muito mais do que uma estratégia terapêutica específica, como uma mobilização que ocorre dentro de um contexto amplo de revisão de fundamentos da vivência social, religiosa e da apropriação científica de conceitos de uma psicologia e psiquiatria ainda em estruturação, que ocorre dentro do contexto americano do período entre guerras (Wendel, 2015).
Nesse processo, podemos identificar três grandes grupos de influência, que, embora muitas vezes se confundam ou se intercruzem, oferecem contribuições específicas. O primeiro, de cunho religioso, englobava as experiências de diversos instituições e movimentos, que já criavam princípios de ação frente à dependência química. Entre eles a Sociedade de Esforço Cristão, O Exercito da Salvação, a Associação Cristã de Moços, o Grupo Oxford, entre outros (White, 2001). O segundo grupo, baseado na apropriação de conhecimentos científicos de autores como C. G. Jung, W. James e W. D. Silkworth, e principalmente de Putnam, Cabot e Coriat, que se envolveram diretamente no Movimento Emmanuel, com contribuições variadas, tanto no que diz respeito à experiência do alcoolismo, quanto no que diz respeito à experiência religiosa. E por fim, oriundo do segundo, um movimento de organização de um modelo terapêutico específico, baseado na experiência da dependência química mesclada com conhecimentos técnicos, que ficou conhecida como Terapia Leiga (Dick B, 1998; Dick B, 2006).

Essa última, embora tenha uma influência dúbia sobre a estruturação do AA (pois este tanto absorve quanto se defende das experiências dela decorrentes, como 
podemos ver na oitava tradição ${ }^{1}$ ), foi um elemento de grande importância na estruturação de um conjunto de compreensões sobre o alcoolismo como doença, bem como da necessidade de se utilizar um modelo terapêutico holístico (mental, social e espiritual) para lidar com o alcoolismo. No entanto, embora se proponha a ser um modelo baseado em uma visão ampla e fundamentalmente vivencial da experiência do alcoolismo, pode-se perceber nas obras dos autores que estruturaram a terapia leiga, uma apropriação de ideias e concepções da psicologia presente à época, que foram sendo também absorvidas, muitas vezes sem uma reflexão crítica ou uma revisão decorrente do avanço dessas mesmas ciências voltadas para o estudo dos fenômenos psíquicos, pelos Alcoólicos Anônimos e outros movimentos de ajuda mútua que seguem o mesmo modelo (Dubiel, 2004).

A proposta do presente artigo é apresentar o desenvolvimento das concepções da terapia leiga através das ideias e práticas dos principais autores dessa concepção de tratamento, bem como as suas concepções de aparelho psíquico e dos fenômenos psíquicos envolvidos na dependência química, principalmente o alcoolismo.

\section{O Contexto do Surgimento da Terapia \\ Leiga}

A terapia leiga surge dentro de um contexto mais amplo de mobilização de esforços de diversos movimentos religiosos que buscavam estruturar formas de apoio aos alcoólatras e suas famílias, e na busca da superação do alcoolismo (Wendel, 2015) que por sua vez se insere em um contexto ainda mais amplo de modernização da sociedade americana, expressos no que foi chamado de Movimento Progressista. Tal movimento buscava fundamentalmente a maior capacidade de regulação econômica por parte do governo federal e sua participação na estruturação e investimentos em políticas de assistência e melhorias na qualidade de vida da população. Com apoio politico na classe média e urbana, incorporou, além dos valores econômicos também valores morais dessas (Filene, 1970).

$\mathrm{O}$ processo de centralização da regulação dos processos econômicos por parte do governo federal tinha também que atuar no sentido de desmontar as estruturas de poder ligadas à grupos que defendiam a

\footnotetext{
1 “Alcoólicos Anônimos deverá manter-se sempre não-profissional, embora nossos centros de serviço possam contratar funcionários especializados.”
} 
descentralização do poder. Nesse sentido, o Saloon, espaço que questionava a moral de classe média, por sua ligação com o álcool, prostituição e o divorcio, é mostrado como o causador das mazelas que a sociedade americana vivenciava, se tornando assim, como um bode expiatório (junto com os grandes empresários), dessas mazelas. No entanto, para além das questões morais, o saloon representava também um espaço de convivência, afirmação, e organização de grupos locais ou de grupos culturais, étnicos ou de classe, principalmente no contexto rural, que não viam como necessariamente benéfica uma centralização do poder no governo federal. Nesse contexto, surge a Lei Seca, que visava, antes de tudo, atacar não só o consumo de bebidas alcoólicas, mas principalmente, uma forma de autoorganização local que se dava por meio da organização social do ato de consumir bebidas alcoólicas (McGerr, 2003).

Embora a Lei Seca tenha encontrado grande êxito na diminuição do crescente consumo de álcool entre os americanos, também gerou uma desestruturação dos serviços de apoio e de políticas públicas voltadas para bebedores compulsivos, para quem a Lei Seca acabava não surtindo tanto efeito, em função da disponibilidade de álcool ainda existir de forma ilegal. Tal fato levou à criação de uma série de ações não governamentais de apoio aos alcoólatras, e à mudança de uma concepção moral do uso excessivo de bebidas alcoólicas para uma percepção do alcoolismo como doença. Essas ações se estruturavam principalmente por meio de movimentos locais de cunho religiosos e de grupos de ajuda mútua (Blocker Jr, 2006).

Embora a discussão de base religiosa fosse mais disseminada na população, já se desenvolvia também todo um movimento dentro do contexto americano de criação de estruturas de acolhimento que mesclava aspectos religiosos e técnicos. Uma das primeiras experiências mais estruturadas nesse sentido foi o Inebriate Asylum Movement, que em um segundo momento se estrutura como o American Association for the Study and Cure of Inebriety, que entre outras ações, cria o Journal of Inebriety, importante órgão de divulgação das experiências de tratamento de dependência química, e de disseminação de uma lógica técnica de abordagem do tema (Weiner \& White, 2007).

Apesar do nome, e do aspecto técnico, não pode-se apresentar esse movimento como um movimento estrita ou exclusivamente manicomial, nos moldes da época, existindo uma diversidade de formas de tratamento e de internação. Algumas questões como uma compreensão do alcoolismo (e de outras dependências, já que o modelo de tratamento não diferenciava o tipo de adicção) como 
doença com um componente psíquico, e consequentemente da necessidade de intervenção médica já estavam presentes. É importante ressaltar que apesar da conotação médica e especializada do tratamento, também já estava presente uma concepção de ajuda mútua entre adictos para a superação da dependência química. No entanto, esse movimento que começara em 1845, aos poucos foi perdendo força, sendo a maioria dos asyluns fechados entre 1890 e 1920, e a concepção médica de tratamento da dependência química, principalmente depois da lei seca, foi se refugiando cada vez mais em manicômios e clínicas especializadas dentro da perspectiva tradicional na época, onde o componente da ajuda mútua, ou os aspectos religiosos eram deixados de lado (White, 1996).

O Movimento Emmanuel, surgido em 1906, na Igreja Episcopal Emmanuel, em Boston buscou-se articular todo esse acúmulo de movimentos religiosos anteriores de acolhimento e tratamento de alcoólatras (Withe, 1998) com aspectos conceituais e metodológicos da psicologia e da psiquiatria para o tratamento da dependência química. Os fundadores do movimento, os reverendos Elwood Worcester (que além da formação religiosa também possuía formação acadêmica na área de psicologia, tendo estudado com Wundt e Fechner) e Samuel McComb, e o médico Isador $\mathrm{H}$. Coriat, estruturam e iniciam, como uma das atividades de sua igreja, um método de cura para as formas variadas de "nervosismo", incluindo alcoolismo e outros vícios. (McCarthy, 1984).

Tais concepções se estruturam inicialmente a partir dos trabalhos de Worcester (2013/1908), que defendia uma forma de pensar a relação entre ciência e religião aplicada a processos de saúde. Baseado em experiências anteriores de mobilização voluntária de serviços médicos em sua igreja e da experiência articuladas com conforto e aconselhamento de base religiosa, e partindo do principio de que Deus cura por muitos meios, articulação entre o trabalho religioso e o científico poderia então fornecer melhores condições para a melhoria das "desordens funcionais mentais" do que a aplicação dessas duas formas de abarcar esses fenômenos ocorrendo de maneira separada.

Segundo Clinibell Jr (1956) o programa de terapia para dependência química desenvolvido por Worcester consistia de três elementos centrais. Terapia de grupo, terapia individual, e serviço de ajuda para reinserção social e familiar. As terapias de grupos ocorriam uma vez por semana, e consistia em encontros onde se mesclavam o culto religioso à palestras de profissionais da saúde ou religiosos sobre temas ligados à dependência. Após essas 
atividades, geralmente também havia jantares, ou atividades sociais no salão social da igreja.

A terapia individual ocorria na clínica, a princípio diariamente, passando a semanal, e era realizado geralmente por pessoas sem formação acadêmica, treinadas na própria clínica Emmanuel. Inicialmente ocorria uma triagem, realizada por médicos, onde pacientes com psicoses ou patologia de origem orgânica eram encaminhados para outros tratamentos. Depois havia três fases. Na primeira buscava-se uma "auto revelação" do paciente, onde os fatos, tanto físicos, mentais, sociais, morais ou espirituais que ele percebia que poderiam estar associados à sua dependência química eram explicitados. Na segunda, de cunho mais religioso, o paciente era orientado em técnicas de oração, para que ele mesmo orasse por si, e entrasse em contado direto com Deus, ao invés de buscar tal fato por meio de intermediários. Por fim, a terceira fase consistia de processos de relaxamento e de sugestão terapêutica, onde pensamentos de autodepreciação e hábitos autodestrutivos eram substituídos por percepções mais positivas sobre si e por desejos por comportamentos mais saudáveis (Clinibell Jr, 1956).

Apesar da percepção de que o alcoolismo era uma doença (que foram divididos em dois grupos, alcoolismo crônico, e a dipsomania), sua indicação para tratamento não partia do fato dele possuir uma doença, como decorre de uma lógica de poder médico, mas de uma decisão do próprio paciente. Estabeleceram-se então como condições para aceitação no tratamento, que o alcoólatra devesse desejar parar de sua própria vontade, e não pela vontade ou imposição de alguém; deveria aceitar a abstinência total da bebida como um dos aspectos de tratamento (que se daria pelo resto de sua vida) e o não acolhimento da pessoa em estado de embriaguez (McPeek, 1945).

O terceiro elemento, o serviço de ajuda para reinserção social e familiar, ocorria por meio dos Visitantes Amigáveis, também treinados pela clínica Emmanuel, que tinham uma tripla função. A primeira era proporcionar aos dependentes um serviço de auxilio social, tanto no sentido de percepção de suas condições de vida, e auxiliá-lo na busca por soluções para aqueles problemas, principalmente ligados a questões econômicas ou familiares. A segunda era de proporcionar uma percepção de aceitação e acolhimento, que ultrapassava as barreiras da igreja e se aplicavam também à vida cotidiana do próprio paciente, onde a sobriedade deveria ser mantida. E a terceira era a de ocupar e possibilitar a reflexão para outros alcoólatras que se mantinham sóbrios, e que consistiam em uma parcela significativa dos membros dos Visitantes Amigáveis. Tal 
fato se mostrou extremamente bem sucedido, não só na aceitação e trabalho desses visitantes, que conheciam de fato as questões vivenciadas por uma alcoólatra, como também na manutenção da sobriedade dos que visitavam (Clinibell Jr, 1956).

$\mathrm{O}$ atendimento social, embora possa aparentar ser um elemento complementar ao tratamento, deve ser entendido como uma expansão dos elementos trabalhados na clínica no nível social, pois a compreensão de sua funcionalidade no tratamento se dava não pelo serviço que era prestado, mas por possibilitar a aplicação do princípio básico de redirecionamento do pensamento e da ação do sujeito frente aos pensamentos e ações ligados à dependência, para os ligados ao serviço ao outro. Tal fato por sua vez se localizava dentro de uma compreensão mais ampla que o problema do alcoolismo não era um problema de vontade, mas de direcionamentos equivocados da mente, que precisavam ser reestruturados, não só internamente, mas também nas atividades sociais dos sujeitos (McCarthy, 1984).

Worcester vai mudar, com o tempo, algumas dessas visões de tratamento, principalmente do processo terapêutico individual, onde as concepções de 1908, expressas em Medicine and Religion, foram sendo aos poucos modificadas pela incorporação de elementos de psicanálise freudiana, e que impactaram principalmente na diminuição da importância da sugestão no processo de tratamento. Essa influência psicanalítica vai aparecer em diversos escritos, e de forma mais sistematizada em Body, Mind and Spirit (Worcester \& McComb, 1932).

No entanto, Worcester não faz uma adoção integral da psicanálise. Isso se dá em função da identificação dos problemas associados ao alcoolismo não decorrerem exclusivamente de questões referentes à estruturação do aparelho psíquico. Além de um prejuízo ou uma incapacidade na integração da personalidade, o que o autor chamou o problema da dependência em si, existia também a necessidade da abstinência para a condução do tratamento, pois o retorno ao uso do álcool constituía-se como uma forma de lidar com os sofrimentos concorrente com a psicoterapia. Nesse sentido, Worcester estabeleceu duas mudanças em relação à análise tradicional: tornar processo psicoterápico mais breve, e combinar o processo de análise com a sugestão. Com essa combinação visava tratar os dois problemas, com a sugestão, procuraria conter a dificuldade dos pacientes de se manterem sóbrios, e com a análise, procuraria identificar e trabalhar as causas que os levavam a beber (Clinibell Jr, 1956). Segundo Dubiel (2004) o movimento Emmanuel pode ser visto como 
um experimento que sintetiza a psicologia com a religião, ou, mais especificamente, $o$ uso da psicoterapia a serviço da religião. No entanto, esse movimento ainda se dava dentro de uma perspectiva mais técnica (considerando também o conhecimento teológico e pastoral como técnicos). É com o surgimento do Jacoby Club, criado por Ernest Jacoby, ligado ao movimento Emmanuel, que o movimento ganha maior ênfase em aspectos como autocuidado, ajuda mútua e camaradagens entre adictos, levando o processo de tratamento mais para as mãos dos próprios dependentes. Suas atividades se concentravam principalmente no apoio a alcoólatras e suas famílias, além da realização de reuniões aos sábados à noite, com comida, entretenimento e palestras. Embora Jacoby Club se separe oficialmente do Movimento Emmanuel em 1913, ainda continuou sob sua influência, principalmente no que toca à compreensão do alcoolismo como doença e sua relação com a religião. Porém, já indicava novas possibilidades de experimentação de formas de abordar o tratamento do alcoolismo.

\section{A Terapia Leiga}

Embora Worcester tenha criado as bases para a compreensão e o tratamento do alcoolismo no método da igreja Emmanuel, os técnicos por ele formados, que foram aos poucos acumulando conhecimentos decorrentes de sua prática cotidiana nas atividades de tratamento, também contribuíram para essa compreensão e para as formas de abordar o alcoolismo. No entanto, tal contribuição partia de pessoas que embora tivessem formação da Clínica Emmanuel, não tinham formação acadêmica nas áreas da saúde nem na área religiosa. Além disso, diferente de Worcester, eram na maioria também alcoólatras, que, tendo participado do tratamento na Clínica Emmanuel, conseguiram manter a sobriedade.

Essas questão são importantes porque o processo de articulação entre religião e ciência, aplicado à atenção a saúde, perde aos poucos centralidade enquanto processo, passando a ser considerado como algo dado enquanto reflexão teórica, e consequentemente, a atividade de reflexão e incorporação de elementos novos que surgiam nos campos da religião e da medicina/psiquiatria, ou da psicologia e da psicanálise vão deixando aos poucos de ocorrer de forma sistemática, devido à ausência de estruturação acadêmica dessa reflexão. Além disso, dado o fato dos terapeutas, além de leigos, serem alcoólatras, a dependência química passa a ser pensada menos a partir do exame de um recorte de objeto de uma ciência particular e mais a partir da integralidade experiencial do alcoolismo do próprio terapeuta leigo. 
Dentre esses terapeutas formados na Clínica Emmanuel, Courtenay Baylor, é o primeiro a se destacar na estruturação de concepções próprias sobre o alcoolismo e seu tratamento. Contratado em 1913 como especialista em alcoolismo, inicialmente atua como um visitante amigável, e depois, como terapeuta na própria clínica. Suas principais contribuições conceptuais sobre o tratamento do alcoolismo estão no livro Remaking a man: One Successful Method Of Mental Refitting (Baylor, 1919), a partir do qual serão discutidos os parágrafos abaixo, de onde o autor levanta a questão da necessidade de considerar, além da Neurose Alcoólica do alcoólatra, também o "ambiente neurótico" que contribuiu para sua "condição nervosa anormal". Existe então uma pequena inflexão no sentido de organizar o trabalho menos a partir de um cunho comunitário, para uma abordagem mais clínica, principalmente a partir da perspectiva individual, embora também houvesse um trabalho com o ambiente familiar e de trabalho.

Baylor estabelece uma diferenciação dos tipos de bebedores compulsivos em três grupos. Os portadores de uma neurose alcoólica, os portadores de psicoses ou demências, e um terceiro grupo, que não possuindo problemas mentais mais graves, tinham uma causa não especificada para o alcoolismo. Sua abordagem teria efeito somente para os do primeiro grupo.
Essa neurose alcoólica caracterizava-se sobretudo como uma percepção equivocada do mundo e da realidade, que se dá a partir do próprio medo, da depressão, irritabilidade, ou imaginação distorcida do alcoólatra, e que se aplica não só ao ato de beber, mas também a vida geral do sujeito. No entanto, tais elementos ocorrem de forma que a causa desses medos e tensões sempre são percebidos como causados por elementos externos e não pelo próprio sujeito.

Tal fato seria comum também nas pessoas normais, inclusive no seu ato de beber. No entanto, essa percepção equivocada, associada principalmente ao uso do álcool, seria uma forma secundária de encarar a vida, que se chocaria no período de sobriedade, com a forma normal de percepção da realidade. A neurose alcoólica seria caracterizada justamente por essa não contraposição de uma forma normal de perceber a realidade e sua crescente substituição pela forma deformada de percepção da realidade fornecida pela embriaguez, mesmo nos períodos de sobriedade. Essas percepções equivocadas acabam por fazer com que o sujeito, por comportar-se frente a elas como se existissem nos moldes de sua percepção, crie as condições, ou atue diretamente para que elas se tornem tais quais essas percepções equivocadas mostravam. Esse é um processo que vai se expandindo aos 
poucos, mas mesmo sua presença ainda não sendo dominante, poderia já indicar uma neurose alcoólica.

A manutenção dessas percepções equivocadas ocorreria pela ausência de desejo de chegar a uma completa normalidade. O alcoólatra perceberia a sim mesmo como um doente, e que esse estado de doença na qual se encontra, o desobrigaria de ter que haver com as demandas da realidade, e que isso deveria ser feito para ele por alguém. Ocorre então uma tensão mental entre uma percepção realista da realidade e uma percepção negativa de si, onde o sujeito se percebe incapaz de lidar com os elementos da realidade. Tal processo, no entanto, se dá de forma inconsciente ao próprio paciente, e mesmo para o observador só seria possível ser percebida em função de este já ter passado pela superação dessa situação, o que expressaria a importância da experiência de superação do alcoolismo como elemento essencial para o terapeuta.

Este deve buscar então, por meio de uma reeducação da mente do paciente, trazer um relaxamento permanente para a mesma. Este vai ocorrer em três fases. A primeira é o relaxamento momentâneo, que ocorre sempre ao início das sessões para que a sessão possa ocorrer. Isso se dá a partir de relaxamentos físicos e mentais, e da eliminação de pensamentos negativos ou destrutivos do fluxo de associações do sujeito. Em seguida o paciente deve ser ensinado a buscar evitar que a tensão volte. Identificando as situações, ambiente, pensamentos ou emoções que levam a desencadear o processo de aumento de tensão que acaba, depois, sustentando essa tensão por si só, ele deve buscar interromper a emergência desses elementos causadores de tensão e, por conseguinte, o fluxo de retroalimentação da mesma. Por fim, considerando que a tensão decorre do investimento da energia do sujeito nos pensamentos e ações negativas e destrutivas, para manter o relaxamento como uma condição duradoura, essa energia deverá ser recanalizada a partir da criação de novos objetos de investimento da energia mental do sujeito, associados a percepções mais positivas de si e do mundo.

Em todo esse processo, as atividades de sugestão e auto-sugestão, bem como a capacidade do paciente de perceber seus pensamentos e sentimentos, são centrais. Essas devem ser consideradas em função de cada pessoa, que vai ter maior ou menor resistência. Porém, o paciente deve, na medida do possível, compreender o processo de tratamento e ir aos poucos se apropriando tanto de sua concepção e método, quanto de sua condução. Tal fato é fundamental para lidar com a maior dificuldade do tratamento, que é a identificação da causa por trás do ato de beber. Essa identificação, no entanto, pode 
conter elementos de difícil aceitação, ou estar carregada de grande sofrimento para o paciente, e só deve ser abordada quando esse se encontrar mais fortalecido.

Além desses aspectos, Baylor também nos mostra a importância de trabalhar com o ambiente no qual o sujeito se encontra. Ele cita o caso da esposa de um paciente, e como esta tinha um tipo de atitude que, se mantida, contribuiria para sabotar o tratamento. Dubiel (2004) nos mostra em outro caso específico, como Baylor insistia na necessidade da família do paciente também participar do processo de tratamento. Mas, nesse segundo caso, diferente do anterior no qual ele somente buscava o apoio da esposa para o tratamento, ele propunha que também a família se submetesse a algumas atividades de tratamento. McCarthy (1984) também comenta nesse sentido que grande parte do tratamento de Baylor era gasto com a família do paciente, que muitas vezes, tinha dificuldade de lidar não só com o alcoólatra, mas com o alcoólatra em recuperação. Além disso, essa atividade de buscar compreender o ambiente também se expandia muitas vezes ao trabalho, onde Baylor procurava os empregadores de seus pacientes para poder também conversar sobre eles.

Podemos perceber então, que apesar de Baylor se manter ligado à clínica Emmanuel, e às percepções de Worcester, traz contribuições em relação à visão deste, pois, os elementos técnicos oriundos da medicina e da religião, embora sejam importantes, passam a ser considerados a partir da experiência concreta da dependência. No entanto, para além da questão teórica e metodológica, podemos notar também uma contribuição de Baylor na forma de instituir o tratamento da dependência química. Enquanto Worcester faz desse tratamento uma forma de ação pastoral, para Baylor ele tem um sentido de existência por si mesmo. Nesse sentido Withe (2012) localiza Baylor como um precursor dentro da prática de Aconselhamento (counseling) dentro do sistema de saúde americano, forma essa de organizar a atividade de tratamento de dependentes químicos que viria a ser formalmente profissionalizada posteriormente.

No entanto, apesar de com sua prática abrir uma série de possibilidades de repensar as concepções, métodos e formas de institucionalização de tratamento, Baylor continuava ligado à clínica Emmanuel e a Worcester. Foi seu paciente, e posteriormente terapeuta leigo por ele formado, Richard Peabody, que desenvolveu esses elementos que aparecem como possibilidade em Baylor, em uma prática profissional autônoma. Formado inicialmente na Clínica Emmanuel, onde fez o tratamento de seu alcoolismo com 
Baylor e trabalhou como voluntário entre 1921 e 1924, Peabody monta um consultório particular e passa a atender sozinho a partir de 1924, ainda em Boston, mudando em 1933 seu consultório para Nova York. Peabody passa a ter sucesso profissional, sendo bastante procurado. Além disso publica alguns artigos em revistas especializadas na área de saúde entre 1928 e 1931, quando publica também seu principal livro, O Senso Comum de Beber (Peabody, 1930), que teria grande influência nas concepções sobre alcoolismo e seu tratamento, principalmente por estabelecer que o alcoolismo, embora possa ser controlado, é uma doença incurável, concepção que foi adotada por muitos não só na área médica como também por movimentos de ajuda mútua, como o Alcoólicos Anônimos (McCarthy,1984).

Além disso, Peabody, realiza algumas modificações em relação à proposta na qual fora formado, da Clínica Emmanuel. Além do modo de institucionalizar seu tratamento, em consultório particular, onde eram cobrados valores significativos, ele retira de seu tratamento a centralidade dos aspectos morais, religiosos e comunitários do tratamento, passando a articular seu tratamento mais dentro dos moldes da medicina convencional da época. Partindo da interpretação do alcoolismo como doença, ele busca articular seu tratamento com a superação de elementos impeditivos a produtividade e eficiência, tanto em relação ao trabalho como em relações sociais (McCarthy, 1984).

Esse elemento atua tanto contra como a seu favor. Como não estava mais amparado pela igreja, para justificar sua prática de tratamento como uma prática religiosa, ficava mais exposto à acusações de prática ilegal da medicina. No entanto, isso forçava Peabody, e outros terapeutas leigos que seguiam sua perspectiva de trabalho, a buscar um trabalho conjunto com médicos, para lhes amparar judicialmente, o que levou, pela eficácia do tratamento, a uma maior aproximação e disseminação de suas ideias em instituições médicas (Dubiel, 2004).

As concepções de Peabody são, em sua maioria, além das aprendidas na clínica Emanuel com Baylor, às quais ele pouco cita de maneira direta, oriundas da psicanálise, e, principalmente, da psicologia individual de Adler. Tais concepções aparecem dispersas na maioria de seus textos, por meio de conceitos como inconsciente, ego, libido, entre outros, mas se dá de forma expressas em $\mathrm{O}$ senso comum de beber (Peadody, 1930) onde o autor dedica um capítulo a discutir a questão da psicanálise, e a defesa das proposições de Adler em detrimento das de Freud, sendo a noção de sentimento de inferioridade, de Adler, a principal causa para compreender o 
alcoolismo. Com isso, Peadody ao mesmo tempo respondia ao questionamento feito por Freud ao Movimento Emmanuel, em função do uso da hipnose e da análise leiga na sua visita aos Estados Unidos em 1909 (McCarthy, 1984), quanto também o questionava, de forma a justificar seu uso dos conceitos psicanalíticos dentro de uma perspectiva de dissidência.

No entanto, apesar de recorrer à Adler (ou a outros autores, em função de justificar o uso da hipnose), Peabody baseia muitas de suas críticas a Freud em função da observação de seus próprios pacientes. Tais observações remetem a compreensão de que o alcoolismo estaria associado a uma fragilidade egóica, sem uma causa definida, mas inerente à própria estruturação do ego e que a essa fragilidade, que seria estrutural, estaria associado um comportamento aprendido de relaxamento das tensões que ameaçam esse ego frágil por meio do uso do álcool ou outras drogas. O álcool teria então uma função dupla: ao mesmo tempo, diminuiria a tensão, mas também fragilizaria ainda mais o ego, tornando-se cada vez mais necessário. Nesse sentido, o ato de beber percebido enquanto sintoma possuia uma função tão importante na causa e sustentação do alcoolismo quanto a fragilidade egóica que a princípio o iniciara (Peabody, 1928).

É também interessante notar que tais concepções psicanalíticas são adaptadas por
Peabody para a crítica social. E embora não cite diretamente os textos sociais de Freud já disponíveis à época (Freud, 1927; Freud, 1930), Peabody (1931) chega a algumas concepções semelhantes, principalmente no que diz respeito à crítica a uma interpretação ou direcionamento religioso ou moral dos comportamentos sociais, e da angústia causada pela percepção da pequenez humana frente às ameaças e necessidades presentes no mundo. No entanto, enquanto Freud passa a analisar a entrega da felicidade em função da segurança, Peabody passa a analisar outra forma de lidar com tal situação que seria o alcoolismo.

Nesse sentido, a ideia central que vai ser o fundamento da terapêutica de Peabody é a noção de relaxamento. Como a causa central do uso do álcool é sua função relaxante, que amenizaria os ataques ao ego fragilizado do alcoólatra, buscar um processo de relaxamento das tensões que causam esses ataques seria uma ação básica para poder começar o tratamento. Isso não implica que não exista uma causa interior que leve a essa tensão, senso essa geralmente associada a crenças autodepreciativas internalizadas pelo sujeito no processo de formação de sua personalidade (Peabody, 1928), mas essas só atuariam em função de uma autopercepção enquanto incapaz de lidar 
situações conflitivas existentes no cotidiano ou nos desejos frente a essas situações.

Tanto a dimensão interna quanto a externa deveriam ser levadas em conta no processo de tratamento, buscando tanto o relaxamento por meio de sugestão e a substituição das concepções negativas de si, quanto por meio da evitação de situações geradoras de conflitos, incluindo, assim como acontecia em Baylor, entrevistas para coleta de informações, visitas e intervenções com a família, ou amigos próximos ao paciente, embora já se expresse um sentido menos comunitário e mais clínico nessas ações, sendo que essa evitação se dá agora, mais como um processo mental, de identificação dos comportamentos e sentimentos relacionados ao consumo do álcool (Peabody, 1930).

A função da família é geralmente pensada também em função da sustentação de condições não só de sustentação do alcoolismo já estruturado, como da possibilitação de novos casos. Isso se dá a partir da atribuição das influências ao ambiente familiar precoce no processo de formação do eu da criança e do ambiente social no qual ele vive na estruturação do alcoolismo. O autor descarta as hipóteses presente à época de causas ou tendências genética, fisiológica, racial ou geográfica do alcoolismo. Um sistema nervoso frágil poderia até ser herdado de pais com sistemas nervosos frágeis, mas pela exposição aos comportamentos que os pais em tais situações teriam em relação à criança, e não por causas biológicas. Geralmente, a situação mais comum a criar essa fragilidade seria uma exposição a um duplo posicionamento frente a criança, ao mesmo tempo de mimo, e de abandono, que levaria a criação de uma dupla percepção e ideal de si mesmo, que por sua vez, causaria um conflito constante na criança e futuramente uma tensão constante no psiquismo do adulto. Essa situação era comumente a encontrada em lares onde um dos membros ou os dois eram alcoolatras (Peabody, 1930).

Essa articulação com questões relacionadas ao ambiente social e familiar na estruturação do alcoolismo, está associada por sua vez à uma consideração mais ampla do consumo de bebidas alcoólicas, que ele não via como um problema por si só (Peabody, 1931). Ele busca primeiro estabelecer o que diferenciava o consumo normal de álcool do patológico, e como identifica-las em um processo diagnóstico. A diferença principal, é que, embora ambos usem o álcool como forma de relaxamento, no caso do bebedor normal esse relaxamento é voltado para um momento específico que termina quando acaba a situação na qual esse se propôs a beber. Já no caso do alcoólatra esse relaxamento visa ser um remédio contra os 
males da vida, não guardando assim relação com um momento específico, mas com a forma de lidar com a vida que o sujeito estabelece de maneira geral.

Mesmo que não implique em um estado de embriaguez constante tal fato já indicaria a situação do alcoolismo. Peabodyr vai então estabelecer cinco situações presentes na descrição do alcoolismo, embora todas só estariam presentes em casos avançados da doença. Elas seriam: Uso de bebidas alcoólicas para superar os efeitos do consumo anterior de álcool, particularmente quando ocorre na parte da manhã; utilização do álcool como um meio de fuga de uma realidade desagradável; aumento constante da dose mensal ou anual; dependência crescente do álcool para situações de diversão e; comportamentos inadequados constantes decorrentes do uso de álcool (Peabody, 1936).

Peabody (1930) vai identificar também outros aspectos, como a presença de retardo mental, psicoses e características de personalidade como comportamentos sistemáticos de mentir ou falta de vinculação afetiva como característica de pessoas para as quais o tratamento na forma como ele propunha não seria indicado. Essa contra indicação também se expressaria caso o ambiente de vida cotidiana do paciente fosse um elemento potencializador do alcoolismo, sendo nesse caso indicada a internação ou afastamento daquele ambiente. Esse tipo de ação, no entanto, deveria ser evitada, e só usada como última solução, devendo-se antes tentar, por conversa com família e amigos, tentar mudar o ambiente no qual o paciente já vivia, incluindo ai o ambiente ou o tipo de trabalho do paciente, de forma que esse fornecesse condições para a sua melhoria.

É interessante nesse caso notar a função da sugestão no tratamento de Peabody, pois, ao mesmo tempo em que se propõem processos constantes de sugestões, esses estão direcionados a estruturar situações de relaxamento, e não em metas ou ações específicas voltadas para a vida cotidiana. A intervenção ambiental, como a participação ou não em atividades onde vão existir bebidas alcoólicas, ou a manutenção de vínculos afetivos com grupos ou amigos construídas no processo e muitas vezes em função do alcoolismo, fica a cargo do próprio paciente.

No entanto, apesar dessa perspectiva de não intervenção direta, busca-se que o paciente possa estruturar um modo de vida, e de adaptação ao ambiente que seja diferente da "adaptação alcoólica ao ambiente" que ele realizava anteriormente, e que muitas vezes pode estar presente e estabelecer os padrões de relacionamento para essas pessoas e grupos, e nos ambientes onde suas atividades ocorrem, embora indique que o mais prudente, seria 
o paciente retirar-se, ao menos temporariamente, dessas "relações sociais molhadas".

Após a identificação das características de personalidade, e dos hábitos relacionados à bebida, Peabody procurava então estabelecer o contrato para o tratamento. Nele, primeiramente o terapeuta busca explicar sua concepção do que é o alcoolismo e suas causas. E a proposta de tratamento associada a abstenção total. Além disso, define aspectos como confidencialidade, periodicidade de sessões e pagamentos. A demanda mais comum é o paciente querer manter, de maneira controlada o hábito de beber. É-lhe mostrada a impossibilidade de tal ação, e indicado que caso ele queira tentar, que poderia fazer isso sozinho, e se não conseguisse, que o terapeuta estaria disponível para o tratamento nos termos já explicitados (Peabody, 1930).

Apesar de seu trabalho conceitual uma das principais contribuições nos textos de Peabody são as reflexões sobre a relação entre as práticas clínicas (com seus elementos psicanalíticos e de hipnose) e a situação específica do alcoólatra. Com uma série de exemplos de casos, o autor mostra tanto situações concretas de enfrentamento necessárias quanto armadilhas às quais o paciente está exposto em função do tratamento. Tais articulações, associadas à experiência concreta da maior parte dos terapeutas que utilizavam seus métodos, foi altamente influente e difundido, não só por se mostrar como um dos primeiros métodos efetivos de tratamento do alcoolismo, mas também por ser passível de ser apropriado e desenvolvido dentro dos moldes acadêmicos e de categorias profissionais já implantados no contexto americano da época, que buscava legitimação social e política, principalmente em relação às perspectivas religiosas (McCarthy, 1984).

A inserção em contextos tradicionais de tratamento obterá uma maior consolidação com um dos alunos / pacientes de Peabody, Francis Chambers. Treinado com terapeuta leigo, dentro do modelo de atendimento privado em consultório, Chambers é o primeiro terapeuta leigo que passa a atender dentro de um modelo multidisciplinar em um contexto hospitalar, e foi aceito na equipe do psiquiatra Edward Strecker, com quem publicou seu principal livro, Álcool: A carne de um homem (Strecker \& Chambers, 1938). Essa participação em uma equipe multidisciplinar teve uma dupla importância. Primeiro, gerou maior legitimidade para a atividade específica do terapeuta leigo, principalmente em função de sua relação com a comunidade psiquiátrica. Em segundo lugar, possibilitou um espaço para que os terapeutas leigos pudessem ter suporte para suas práticas, tanto do ponto de vista institucional, quanto 
do ponto de vista técnico, em função do acesso a grupos de discussão técnica e à supervisão clínica de um profissional treinado na área de saúde, geralmente um psiquiatra. É interessante aqui ressaltar, que essa proposta de supervisão, por um viés técnico foi um caminho da terapia leiga. Em paralelo, a disponibilização de um suporte que se manteria leigo também se desenvolveu, mas dentro de outras propostas de tratamento, como o AA. (White, 2000).

Esse é um ponto importante quando se analisa a contribuição de Chambers ao tratamento do alcoolismo, pois, embora apresente uma melhor estruturação de um discurso técnico, em termos concretos, dentro desse âmbito técnico não realiza grandes avanços em relação à Peabody, ou às concepções psiquiátricas da época. É na demarcação da necessidade de uma proposta psicoterapêutica, realizada dentro de um contexto técnico interdisciplinar como a proposta mais adequada ao tratamento do alcoolismo que está sua grande contribuição.

Isso fica explicito quando o autor vai comparar o tratamento psicoterápico com outros dois disponíveis no momento, o tratamento medicamentoso (por meio do Antabuse), e o tratamento comunitário leigo (realizado pelo AA). Do primeiro contesta sua incapacidade de lidar com a causa do alcoolismo, só gerando a impossibilidade de beber no alcoólatra, comportamento esse que tem a função de gerar um alívio dos conflitos psíquicos decorrentes da neurose alcoólica, e que, sendo impossibilitado pelos efeitos do Antabuse, só geraria uma piora no quadro do paciente, levando a quadros mais graves, incluindo a morte. Do segundo, embora indique sua importância em função do seu baixo custo e fácil acesso, questiona que apesar de oferecer suporte para o dependente, esse se expressa como uma muleta para sustentar uma situação de abstinência, mas não possibilita uma cura da neurose alcoólica, sendo necessário não o atendimento ao alcoólatra, mas ao sofrimento da personalidade de cada sujeito, que encontra no alcoolismo uma saída (Chambers, 1953).

Essa concepção se expressa como uma forma também de crítica às concepções psiquiátricas da época, que identificava uma diversidade de tipos de alcoolismo. Algumas características de personalidade, como a imaturidade emocional, e a introversão, seriam elementos de vulnerabilidade ao alcoolismo, mas não suas causas. A existência de um núcleo neurótico e o aprendizado da bebida alcoólica como forma de fugir da realidade é que seriam as principais causas do alcoolismo. No entanto, essas condições poderiam se expressar em sujeitos de diferentes estruturas de personalidades, não havendo um tipo específico de neurose 
alcoólica, mas um conjunto de fatores, que, associados a um núcleo neurótico de diferentes tipos, causariam o alcoolismo (Strecker, Chambers, 1938).

O processo psicoterápico, realizado dentro de um contexto mais amplo de uma equipe multidisciplinar seria então o modelo capaz de possibilitar o tratamento do alcoolismo. Essa perspectiva fica ainda mais clara quando se percebe que a concepção de um ambiente propício para o desenvolvimento do alcoolismo é expresso em termos de higiene mental, e sua aplicação a contextos variados, que vão, desde o trabalho, a família, e as condições sociais e educacionais. Nesse sentido Chambers se diferencia de Peabody, pois o consultório particular deixa de ser o espaço ideal para o tratamento do alcoolismo, passando esse a ser direcionado para um modelo de sistema de saúde mais amplo, que vai desde ações sociais e sanitárias, até o processo de hospitalização, sendo o processo psicoterápico um dos elementos constitutivos desse sistema (Chambers, 1937).

\section{Conclusão}

A construção da compreensão sobre o alcoolismo, e das ações voltadas para uma terapêutica ou profilaxia de problemas a ele associados, passa não só pela fundamentação teórica subjacente a essa construção, mas também pelas possibilidades concretas de implementação das mesmas, e das formas de institucionalização nas quais essas práticas e compreensões estão inseridas. Nesse sentido, o estudo da terapia leiga, se mostra como um campo rico para entender a construção desses processos em função de sua pluralidade de dinâmicas e de formalizações institucionais.

Essa pluralidade ganha ainda mais importância pelo caráter muitas vezes inaugural que estabeleceu em diversos aspectos da compreensão e dos modos de abordar e de tratar o problema do alcoolismo e da dependência química, característica essa que o coloca como uma referência para a elaboração dos diversos modelos de abordar a questão desenvolvidos posteriormente. No entanto, essas referências, que se estruturaram tanto dentro do aspecto conceitual como na estruturação de práticas e formas de institucionalização do tratamento do alcoolismo, ocorreu, apesar de uma construção conceitual formal, difundida a partir de livros e periódicos científicos, fora de um contexto de revisão acadêmica sistemática, e foi muitas vezes difundida e assimilada da mesma forma pelos movimentos e instituições influenciadas. Conceitos como os da psicanálise, que variaram muito em função do estabelecimento de novos conceitos 
propostos por Freud a partir dos anos vinte, ou mesmo conceitos relacionados à sugestão hipnótica, por exemplo, muitas vezes se foram adotadas como verdades intuitivas, não sendo revistas ou analisadas posteriormente.

A análise da presença desses conceitos nos movimentos como o AA ou outros grupos semelhantes merece um estudo a parte. Porém, procurou-se com esse texto realizar um trabalho necessário anteriormente para isso, trazendo à tona tanto os conceitos quanto sua evolução no presente artigo, bem como a disponibilização de algumas das principais referências sobre o tema, de forma a possibilitar pesquisadores uma inserção inicial mais fácil sobre o tema, pois, além da falta de textos em língua portuguesa, existe uma grande lacuna de estudos sobre o tema da Terapia Leiga no Brasil. Esperamos então, poder fornecer, ainda que introdutória, uma fundamentação para ampliação do debate sobre o tema.

\section{Referências}

Alcoólicos Anônimos (1971) Os doze passos e as doze tradições. JUNAAB (Junta de Serviços Gerais de Alcoólicos Anônimos do Brasil): São Paulo.

Blocker Jr, J. S. (2006) Did Prohibition Really Work? Alcohol Prohibition as a Public Health Innovation. American Journal of Public Health, 96(2): 233-243. Recuperado em 26 de outubro de 2016 de https://www.ncbi.nlm.nih.gov/pmc/articles/PMC1470475/.

Chambers, F.T. A Psychological Approach in Certain Cases of Alcoholism. Mental Hygiene, 21:67-78, $1937 . \quad$ Disponível em http://www.silkworth.net/emmanuel_movement/01009.htm.

Chambers, F.T. Analysis and Comparison of Three Treatments: Measures for alcoholism: Antabuse, The Alcoholics Anonymousapproach, and Psychotherapy. British Journal of $\begin{array}{lllll}\text { Addiction, } & \text { Vol. } & 50, & 1953 . & \text { Disponível }\end{array}$ http://silkworth.net/emmanuel_movement/01010.htm.

Clinebell Jr, H.J. (1956) Understanding and Counseling the Alcoholic. Recuperado em 05 de novembro de 2016 de http://media.sabda.org/alkitab-2/ReligionOnline.org\%20Books/Clinebell,\%20Howard\%20J.\%20Jr.\%20$\% 20$ Understanding $\% 20$ and $\% 20$ Counseling\%20the\%20.pdf

Dick B. A New Way Out: New Path--familiar Road Signs--our Creator's Guidance. Good Book Publishing Company: Epsom, England. Recuperado em 06 de outubro de 2016 de 
Dick B. (1998) The Oxford Group and Alcoholics Anonymous: A Design for Living That Works. Paradise Research Publications, Inc.; Kihei, Maui, Hawaii: Recuperado em 05 de outubro de 2016 de www.dickb.com/Oxford.shtml.

Dubiel, R.M. (2004) The road to fellowship: the role of Emmanuel Movement and the Jacoby Club in the development of Alcoholics Anonymous. Lincon, NE: Universe Inc.

Filene, P. G. (1970) An Obituary for "The Progressive Movement". American Quarterly, 22 (1) 20-34. Recuperado em 26 de outubro de 2016 de http://www.trinityhistory.org/AmH/Progobit.pdf.

Freud, S. (1930/1996) Mal-Estar na Civilização. Obras Psicológicas Completas de Freud Edição Standart Brasileira - Volume XXI - Editora Imago - Rio de Janeiro 1996.

Freud, S. (1927/1996) O futuro de uma ilusão. Obras Psicológicas Completas de Freud - Edição Standart Brasileira - Volume XXI - Editora Imago - Rio de Janeiro.

Garcia, Maria Lúcia Teixeira; Leal, Fabíola Xavier; Abreu, Cassiane Cominoti (2008) A política antidrogas brasileira: Velhos dilemas. Psicologia \& Sociedade; 20 (2): 257-266. Recuperado em 04 de outubro de 2016 de http://www.scielo.br/pdf/psoc/v20n2/a14v20n2.

Mota, L. A. (2004) A Dádiva da sobriedade: ajuda mútua nos grupos alcoólicos anônimos. Editora Paulus, São Paulo.

Pillon, Sandra Cristina; Luis, Margarita Antonia Villar (2004) Modelos explicativos para o uso de álcool e drogas e a prática de enfermagem. Revista Latino Americana de Enfermagem; 12(4):676-82. Recuperado em 04 de outubro de 2016 de http://www.scielo.br/pdf/rlae/v12n4/v12n4a14. $\quad$ DOI $\quad 10.1590 /$ S010411692004000400014.

McCarthy, k. (1984) The Emmanuel Movement and Richard Peabody. Journal of Studies on Alcohol, Vol.45, No.1. Texto recuperado em 06 de outubro de 2016 de http://silkworth.net/emmanuel_movement/01001.htm.

McGerr, M. (2003) A Fierce Discontent: Rise and Fall of the Progressive Movement in America, 1870-1920. New York: Free Press.

McPeek, F. W. (1945) The Role of Religious Bodies in the Treatment of Inebriety in the United States. In H. W. Hagard. Alcohol, Science and Society. Jornal of Studies in Alcohol, New Haven, CT. 403-418. Recuperado em 06 de outubro de 2016 de http://silkworth.net/emmanuel_movement/01002.htm.

Peabody, R.R. (1928) Psychotherapeutic Procedure in the Treatment of Chronic. Boston Society of Psychiatry and Neurology. Recuperado em 10 de novembro de 2016 de http://silkworth.net/emmanuel_movement/01007.htm.

Peabody, R.R. (1930) The Common Sense of Drink. Boston: Little Brow \& Co. Recuperado em 10 de novembro de 2016 de http://www.williamwhitepapers.com/pr/1930\%20Peabody\%20Common\%20Sense\%20of $\% 20$ Drinking.pdf. 
Peabody, R.R. (1931) Why prohibitioin has failed. The American Mercury, 22(88), 385-391. Recuperado em 10 de novembro de 2016 de https://www.unz.org/Pub/AmMercury1931 apr-00385.

Peabody, R.R. (1936) The Danger Line of Drink. Scribners Magazine, pp 370-372. Recuperado em 10 de novembro de 2016 de http://www.unz.org/Pub/Scribners-1936jun-00370.

Silva Figueiró, M. E. (2014) Suporte psicossocial para familiares de dependentes químicos e políticas sociais brasileiras. VI Congreso Internacional de Investigación y Práctica Profesional en Psicología XXI Jornadas de Investigación Décimo Encuentro de Investigadores en

Psicología del MERCOSUR. Buenos Aires. 2014. Recuperado em 04 de outubro de 2016 de http://www.aacademica.com/000-035/495.pdf.

Strecker, E. A.; Chambers F. T. (1938) Alcohol: One Man's Meat. New York:The Macmillan Company. Recuperado em 18 de outubro de 2016 de https://babel.hathitrust.org/cgi/pt?id=mdp.39015072273371;view=1up;seq=71. DOI 10.1097/00000446-193810000-00039.

Wendel, R. (2015) Prohibition and Religion: Mennonite Brethren and the Temperance Movement, 1900-1940s. Cotemporary Menonite Scholarship, 69, 00-00. Recuperado em 18 de outubro de 2016 de https://ml.bethelks.edu/issue/vol-69/article/prohibition-andreligion-mennonite-brethren-and-th/.

Weiner, B. \& White, W. (2007). The Journal of Inebriety (1876-1914): history, topical analysis and photographic images. Addiction, 102, 15-23. DOI 10.1111/j.1360-0443.2006.01680.x.

White, W. (1996) Pathways: From the culture of addiction to the Culture of Recovery: A travel guide to addiction professions ( $2^{\mathrm{a}}$ edicção) Hazelden: Center City, MN. Publicação original em 1990.

White, W. (1998). Slaying the Dragon: The History of Addiction Treatment and Recovery in America. Bloomington, IL: Chestnut Health Systems.

White, W. (2000). The history of recovered people as wounded healers: I. From native America to the rise of the modern alcoholism movement. Alcoholism Treatment Quarterly, 18(1), 1-23. Recuperado em 10 de fevereiro de 2017 de http://www.williamwhitepapers.com/pr/2000RecoveringPeopleWoundedHealersI.pdf.

White, W. (2001) Pre-AA Alcoholic Mutual Aid Societies. Alcoholism Treatment Quarterly 19(1):1-21. Recuperado em 01 de novembro de 2016 de http://www.williamwhitepapers.com/pr/2001Pre-AARecoveryMutualAidSocieties.pdf.

White, W. (2012) A brief history of recovery orientation in addiction counseling. In NAADAC (2012) Recovery to Practice Situational Analysis. Alexandria, VA. Recuperado em 08 de novembro de http://t.williamwhitepapers.com/pr/2012\%20History\%20of\%20Recovery\%20Orientation $\% 20$ in\%20Addiction\%20Counseling.pdf. 
Worcester, E. (2013) Religion and Medicine. The Moral Control of Nervous Disorders. Forgotten Books: London, U.K. Publicação original em 1908.

Worcester, E. \& McComb, S. (1932) Body, mind and spirit. New York: C. Scribner's Sons.

\section{O autor:}

Sanyo Drummond Pires possui graduação em Psicologia pela Universidade Federal de Minas Gerais (1999), mestrado em Psicologia Social pela Universidade Federal de Minas Gerais (2005) e doutorado em Psicologia pela Universidade São Francisco (2013). Atualmente é professor da Universidade Federal da Grande Dourados (UFGD), atuando principalmente nas áreas de Psicologia e Economia Solidária, e Saúde Mental do Trabalhador. E-mail: sanyodrummond@yahoo.com.br

Recebido em: 25/07/2017

Aprovado em: 26/12/2017. 